\title{
Institutional Complexity and Paradox Theory Complementarities of Competing Demands
}

Organizational success increasingly depends on leaders' abilities to address competing demands simultaneously. Scholars have applied both institutional theory and paradox theory to better understand the nature and responses to these competing demands. These two lenses diverge in their understanding and responses to tensions. Institutional theory depicts competing demands emerging from divergent field level pressures, and stress their contradictory and oppositional nature. Organizational responses vary from making tradeoffs and choosing pressures with which to conform to seeking strategies for engaging both and managing conflict. Paradox theory locates competing demands as inherent with organizational systems, surfaced through environmental conditions, individual sensemaking or relational dialogue. According to these scholars, paradoxes are contradictory, interrelated and persist over time, demanding strategies for engaging and accommodating tensions but not resolving them. In this essay, we highlight these distinctions, and argue that drawing from both of these lenses will results in rich, generative theorizing to better address key challenges in the world. We identify specific areas where future research can benefit from such integration. 


\title{
Institutional Complexity and Paradox Theory Complementarities of Competing Demands
}

\author{
Wendy K. Smith and Paul Tracey \\ Organizations and their leaders increasingly face competing demands. Studies depict tensions
} between profits and purpose (Jay, 2013; Battilana and Dorado, 2010; Tracey et al., 2011; Ashforth and Reingen, 2014; Besharov, 2014), today and tomorrow (Andriopoulos and Lewis, 2009; Smith, 2014; Luscher and Lewis, 2008), short term and long term (Slawinski and Bansal, 2015; Reinecke and Ansari, 2015) and global integration and local distinctions (Smets et al., 2015). This mounting phenomenon motivates an expanding body of research seeking to understand the nature, responses and implications of competing demands in organization.

As one lens to explore these competing demands, institutional theory highlights divergent pressures from field level actors and investigates organizational and individual approaches to avoid, resolve or negotiate these tensions (Greenwood et al., 2011). Paradox theory offers another lens. Paradoxes are "persistent contradictions between interdependent elements" (Schad et al., 2016). This lens depicts tensions as inherent within organizational systems and seeks approaches to embrace their persistent nature. Deriving from distinct origins with different underlying assumptions, these lenses developed mainly independent of one another with few papers drawing from both (for exceptions see Jay, 2013; Battilana et al., 2014). Yet, together, the insight from these lenses can complement one another, generating richer and more diverse theorizing about competing demands and environmental complexity. In this essay, we seek to advance research on competing demands, tensions and complexity by comparing and contrasting institutional theory and paradox theory. We identify divergent assumptions, surface complementary understandings, and generate gaps for future research. We hope these reflections can inspire scholars to integrate ideas across theoretical traditions to result in more rich and diverse 


\section{Institutional Complexity and Paradox Theory -Underlying Assumptions}

While institutional complexity and paradox theory both explore how organizations address competing demands, their underlying assumptions and approaches diverge. We compare these theoretical traditions in three primary domains, 1) source 2) nature and 3) challenges and responses.

Insert Table about here

\section{Source of Competing Demands}

Emerging from a sociological tradition, institutional complexity scholars depict competing demands as emanating from societal level expectations. Greenwood and colleagues (2011) describe institutional complexity as the situation that arises when organizations "confront incompatible prescriptions from multiple logics.” (p. 317). Institutional logics offer overarching sets of principles that provide guidelines to understand and behave in social situations (Thornton et al., 2012; Friedland and Alford, 1991). While logics manifest at multiple levels, scholars depict a delineated set at the societal level that are shared across contexts (Thornton et al., 2012). Organizations and their leaders adhere with expectations from these logics in order to gain legitimacy and cultivate necessary resources. Complexity arises when organizations face multiple, incompatible logics simultaneously. Pache and Santos (2010) argue that such situations arise with more fragmented and moderately centralized fields. For example, organizations experience more competing demands from multiple stakeholders in fields such as health care (Goodrick and Reay, 2011; Reay and Hinings, 2009), professional services (Smets et al., 2015; Smets et al., 2012) and community banking (Battilana and Dorado, 2010). Alternatively, organizations situated at the interstices of multiple fields, such as social enterprises, face competing demands from these various fields (Besharov and Smith, 2014; Tracey et al., 2011).

Paradox scholars offer a more varied, and often contested, perspective on the locus of competing demands in organizations. Paradox depicts contradictory, yet interdependent elements that persist over time (Lewis, 2000). The concept of paradox draws from a long history, which informs multiple perspectives about the source and ontology of competing demands in organizations. Early insights 
emerged as philosophers, theologians and logicians grappled with irrational, cyclical phenomena, often using these challenges to provoke deeper thinking (see e.g. Schad et al., 2016; Chen, 2002). The statement "I am lying" offers a classic example where truth leads to falsehood, and falseness uncovers truth.

Drawing from these roots, scholars depict such cyclical absurdities as inherent within social systems. Paradoxes emerge as organizational boundary setting fosters distinctions, fuels opposites, and embeds these contrasting elements within an existing system (Ford and Backoff, 1988). For example, Audia, Locke and Smith (2000) summarize the inherently paradoxical nature of success and failure in organizations; increased success exposes firms to greater potential for failure, while increased failure motivates the potential for greater success. Examples abound of market leaders being overtaken by new entrants in industries such as in film and imaging (Tripsas and Gavetti, 2000), computer hardware and software (Christensen and Bower, 1996), newspapers (Gilbert, 2005), etc. Similarly, Farjoun (2010) depicts change and stability as paradoxes inherently embedded in organizational systems. Change takes hold more effectively in stable systems, while organizational stability depends on ongoing fluctuations in response to environmental demands. Weick, Sutcliffe and Obstfeld (1999) depict high reliability systems such as high speed trains as enabling stability through persistent changes. Similarly, Klein, Ziegert, Knight and Xiao (2006) find that stable, competent care in an emergency room depended on ongoing shifts in leadership.

More recently, organizational paradox scholars drew inspiration from psychoanalysts such as Jung, Frankle, Adler, Watslewick, and Batson, who sought to understand how individuals experience and respond to competing demands in their own lives, including tensions between love and hate, good and evil, or self and other (see e.g. Smith and Berg, 1987; Kets de Vries, 1995), situating paradoxes within the individual, and emerging from our social construction. According to this point of view, paradoxes emerge when individuals juxtapose competing demands within the same space and time (Poole and Van de Ven, 1989). Extending this focus on social construction, other scholars describe paradoxes surfacing from relational dynamics through dialogue, social interactions and practices (Jarzabkowski and Le, 2016; Putnam et al., Forthcoming). Bridging these varied positions, Smith and Lewis (2011) depict paradoxes as 
inherent in systems, yet often latent and unobserved. Tensions become salient to actors either through individual sensemaking and relational dynamics, or through environmental conditions of scarcity, plurality and change. Scarcity emphasizes limited resources, which generates conflict between opposing demands. Plurality involves multiple stakeholders which highlights competing needs. Finally change raises differences and tensions across varied time horizons (see Smith and Lewis, 2011).

\section{Nature of Competing Demands}

The varying sources of tensions across these different theories impact our understanding of the number of competing demands and the relationship between them. Institutional theory assumes that organizations can experience pressures to adhere to multiple logics simultaneously. Studies often simplify this assumption, focusing primarily on the relationship between two competing logics (Greenwood et al., 2011), although scholars explore how organizations respond to three (Greenwood et al., 2010) or four logics (Goodrick and Reay, 2011; McPherson and Sauder, 2013).

Paradox studies emphasis on dual tensions reflects underlying theoretical assumptions.

Boundaries foster dualities in direct opposition from one another - A and not A, light and dark, today and tomorrow, stability and change (Smith and Berg, 1987; Quinn and Cameron, 1988). These two elements attract and repel one another. Scholars question whether and how three relationships between three or more elements shifts from direct opposition to one another, while also adding exponentially more ties between elements (i.e. Ford and Ford, 1994). Two elements involve one relationship, three elements involve three interactions, while four elements involve six connections, etc. These elements can organize into factions with one another, leaving scholars to question how higher numbers of relationships conform to the dynamics of paradox, or demand alternative theoretical insights.

Institutional complexity and paradox theory also differ in how they depict relationships between competing demands. Institutional theory describes societal logics as either complementary or contradictory (Besharov and Smith, 2014). By definition, complexity focuses on logic incompatibilities situations involving contradictory prescriptions for action and therefore emphasizing conflicting relationships (Greenwood et al., 2011). Studies of institutional complexity explore the possible 
approaches to minimize these conflicts, including making tradeoffs and in some conditions choosing to conform to some pressures over others (Quirke, 2013). In contrast, paradox scholars emphasize both the contradictory, as well as interdependent nature of paradoxical tensions (Lewis, 2000; Smith and Lewis, 2011). Contradictions emphasize the differential, oppositional nature of elements, while independence, captures the synergies, integration and mutual constitution, that persist over time (Schad et al., 2016). The boundaries of one element inform and identify the boundaries of the other. For example, stability defines, and is defined by, change, and vice versa. This contradictory interdependence distinguishes paradox from other tensions such as dilemmas, tradeoffs and dichotomies, which all emphasize contradictory relationships but not interdependence. As a result, these tensions can be resolved by making choices between alternative outcomes. Dialectics emphasize contradictory and interrelated elements, but assume that these relationships morph over time. A thesis and antithesis change to form a synthesis, which becomes a new thesis for a new antithesis. In contrast, paradoxes emphasize a persistent, underlying relationship between opposing forces that cannot be resolved, but must be accepted and accommodated. Tensions between today and tomorrow, individuals and collectives, integration and differentiation persist in organizational systems.

\section{Challenges and Responses to Competing Demands}

Differing depictions of the nature of competing demands impacts inherent challenges and organizational responses. As we noted earlier, scholars primarily emphasize the organizational obstacles and challenges that emerge from complexity. By focusing on incompatibilities, these scholars highlight competing demands as predominantly problematic, raising internal conflicts and external legitimacy concerns. Competing logics often manifest within different individuals and groups in organizations, creating tensions as these groups become locked in competition in the face of strategic decisions (Ashforth and Reingen, 2014; Glynn, 2000) and individual practices (Besharov, 2014). In the extreme, intractable conflicts can lead to organizational faltering or demise (Battilana and Dorado, 2010). Moreover, facing pressures to adhere to incompatible demands from external referents can result in choosing one demand, which at the extreme, results in organizational failure. Examples from 
microfinance and social entrepreneurship suggest how organizations falter when they prioritize either their market logics or their social mission logic (Battilana and Dorado, 2010; Tracey et al., 2011).

Alternatively, scholars depict paradoxes as fueling both challenges and opportunities. Paradoxes can raise uncertainty and anxiety, resulting in defensive responses to reject and resist paradoxes (Vince and Broussine, 1996; Lewis, 2000), and leading to detrimental vicious cycles (Sundaramurthy and Lewis, 2003). Overcoming these defensive reactions and embracing competing demands can alternatively fuel virtuous cycles, foster creativity and enable long term sustainability (Rothenberg, 1979; Smith et al., 2011; Cameron, 1986). For example, Smith (2014) demonstrated how commitments to explore new possibilities while exploiting existing products fueled ongoing conflicts and tensions among strategic business unit top management team members in a high-tech firm. Teams that decided to resolve these tensions by choosing to either explore or exploit declined in the short term and ultimately needed to address the alternative strategy in the long term. In contrast, top management teams that adopted approaches for engaging both strategies simultaneously achieved both short term improvements and long term success.

Enabling such virtuous cycles involves strategies to live with and accept paradoxes over time. Luscher and Lewis (2008) find that middle managers at LEGO could effectively address the tensions between change and stability when they shifted from searching for a long term resolution between the old and the new, change and stability, and instead started to explore 'workable certainties' that allowed them to push forward amidst the ongoing pressure of today and tomorrow. Scholars have pointed to individual cognitive practices to do so including paradoxical framing (Smith and Tushman, 2005; Miron-Spektor et al., 2011; Bartunek, 1988) and Janusian thinking (Rothenberg, 1979) which demands a change of mindset from either/or framing to both/and approaches. Others have noted that managing paradoxical tensions challenges emotional reactions (Vince and Broussine, 1996). Studies that explore responses to these emotional reactions remain scant (Schad et al., 2016), though some scholars have begun to explore practices for doing so, including the use of humor to signal and move beyond individual level anxiety and defensiveness in the face of paradoxical tensions (Jarzabkowski and Le, 2016; Beech et al., 2004). Others 
highlight practices that involve differentiating - actively seeking distinctions between alternative demands, while simultaneously integrating - exploring synergies and interactions (Andriopoulos and Lewis, 2010; Smith, 2014; Smets et al., 2015). For example, in the high-tech firm, Smith (2014) found that the strategic business unit top management teams that more effectively explored and exploited simultaneously did so by creating distinct structures, roles, rewards, and discourse that helped emphasize differences between the existing product and innovation, while also developing an overarching identity, integrated roles, and joint discourse to stress the synergies between competing demands.

\section{Future Theorizing through Multiple Lenses}

Although institutional complexity and paradox theory diverge in their underlying assumptions and emphasis, we suggest that these alternative insights can complement one another, and generate fruitful avenues for future research. We highlight some of these areas below.

1. Salience of competing demands - Paradox theory assumes that every organization embeds competing demands, though such tensions may be latent. From this perspective, environmental conditions such as plurality, change and scarcity surface latent tensions (Smith and Lewis, 2011). Institutional complexity theory, on the other hand, focuses more explicitly on the environmental conditions themselves, suggesting that specific field-level characteristics may shape how competing demands manifest in organizations (Pache and Santos, 2010). For example, the field position of a given organization or set of actors profoundly influences the experience of institutional pressures (Battilana, 2006; Wright and Zammuto, 2013). Peripheral actors may be buffeted by competing demands, while resources available to central actors can offer a degree of protection. Other scholars highlight differing dynamics in mature and emerging fields (Wooten \& Hoffman, 2008). In emerging fields, the fast pace of environmental change casts competing demands in flux, and offers unclear prescriptions for organizational actors. By contrast, in mature fields with more stable environments, tensions are well understood, and so there is relative clarity about which pressures are salient. Institutional theory has the potential to support paradox theorists' understanding of tension salience by providing a theoretical basis and vocabulary for conceptualizing the role of the environment. Similarly, paradox scholars point to 
leadership and individual sensemaking as an alternative form of surfacing latent tension (Smith and Lewis, 2011; Smith and Tushman, 2005; Bartunek, 1988) challenging institutional complexity scholars to explore in more depth the role of individual agency within organizations. Together these lenses question how environmental conditions and individual sensemaking work together to make salient underlying tensions.

2. Static and dynamic responses - Institutional complexity emphasizes more static, structural responses to complexity. For example, scholars argue that multinational corporations face a fundamental "institutional duality" when creating a subsidiary in a new country - a set of tensions that require them to conform to both the institutional pressures from the country in which they are headquartered and from the host country in which the subsidiary is located (Kostova and Roth, 2002). Scholars depict these tensions as predominantly stable, allowing MNCs to adopt particular "business models, practices, and structures established as standard" in a given organizational field (Kostova et al., 2008: p. 998-999). In a similar vein, institutional theorists conceptualize hybridization as a structural response to complexity, but tend not - with some important exceptions (i.e. Raaijmakers et al., 2015) - to consider the fluidity of hybrid organizing. Indeed, Battilana and Lee (2014) explicitly encourage institutional theory scholars to move from depicting established, fixed hybrid organizations that embed competing demands and instead to explore hybrid organizing as mutable and adaptable processes.

In this respect, paradox theory offers important insights for institutional theory. Specifically, paradox theory stresses dynamic and agentic responses to complex tensions, and invites scholars to explore how these tensions are experienced over time as well as the capacity of actors to enact different responses. In other words, paradoxical thinking can inform research on institutional complexity by encouraging researchers to investigate processual dynamics in response to tensions. For example, research on ambidexterity (Raisch and Birkinshaw, 2008) offers a way of conceptualizing dynamic strategic action in the face of competing demands. There may an interesting intersection with research on institutional work (Lawrence et al., 2009), which has been curiously marginal to institutional complexity (Zilber, 2013). Moreover, paradox theorists' longstanding interest in emotion may also help institutional theorists 
develop a more dynamic view of how actors respond to competing demands (Smith \& Lewis, 2011). Such a connection may be especially timely given institutional theorists' recent interest in the relationship between emotion and institutional dynamics (Voronov and Vince, 2012; Creed et al., 2014). This interest remains embryonic, but some institutional theorists have begun to incorporate an explicit focus on emotion into their empirical work. For example, Wright et al. (forthcoming) examine how physicians' experience of "moral emotions" precipitated by "value conflicts" support the maintenance of professional values. Similarly, Tracey (forthcoming) studies how members of a religious movement purposefully elicit guilt and empathy to "persuade" other actors to switch from an agnostic institutional logic to an evangelical Christian one.

3. Real world experiences of tensions - Future research at the intersection of paradox theory and institutional complexity can further explore the everyday experience of tensions in organizations by the actors who inhabit them. Studies adopting both an institutional complexity and paradox lens share a common weakness: the tensions studied are often 'unearthed' by researchers a priori. Researchers from both traditions often set out to explore in organizations key tensions depicted in the literature. As a result, tensions may become reified and detached from the 'reality' of organizational life. For example, many social entrepreneurs, and indeed corporations, frame social and environmental problems as market opportunities; they are explicitly resistant to the idea - pushed in both institutional theory and paradox theory - that the pursuit of social and market aims simultaneously represents a tension in which each objective is traded off (Drucker, 1984; Zahra et al., 2009). Of course, many social entrepreneurs do perceive social and market demands as competing and explicitly say that they struggle to contain them (Battilana and Lee, 2014). Alternatively, researchers may focus narrowly on the experience of one particular tension, when real world actors experience multiple competing demands interwoven with one another. While there is some important work in both institutional theory (i.e. Nigam and Ocasio, 2010) and paradox theory (i.e. Murnighan and Conlon, 1991) that develop tensions and contradictions inductively, researchers working in both traditions could develop more compelling insights by 
'discovering' tensions inductively and by seeking, as far as is possible, to view the world from the perspective of their informants, rather than assuming a set of tensions at the outset.

Combining paradox and institutional theory may actually help overcome these shortcomings: one of the interesting differences between the two perspectives is that paradox theory avoids the tendency within institutional theory to assume that all tensions are somehow institutionally derived - they can, of course, be local and specific. The paradox perspective avoids the insistence often characteristic of institutional theory that everything has to be grounded in broader field or societal processes. Relatedly, both lenses often focus on the nature of the tensions, but offer less insight into how organizational members differentially experience them. For example, senior leaders and middle managers may experience different competing demands, or may find that the challenges associated with these competing demands vary (see e.g. Luscher and Lewis, 2008; Huy, 2002). Researchers in both paradox and institutional theory can offer more nuanced insight into how organizational members experience competing demands (i.e. Smets et al., 2015), and how these experiences differ across individuals.

4. Addressing grand challenges - Finally, both institutional complexity and paradox theory begin with the assumption that competing demands increasingly arise in response to mounting societal challenges. Faster paced technology, expanded globalization and interconnection, and more diverse markets precipitate new competing demands and intensify existing ones. While such developments may foster creativity and innovation that trigger positive social change, they also carry with them significant hazards that risk unleashing potentially destructive social and environmental forces. These changes have been accompanied by increased polarization of rich and poor both within and between countries, leading to 'winners' who are able to participate in an increasing opportunity set, and 'losers' who are essentially excluded from the basic social and market structures required to lift them out of poverty. Other "grand challenges" (Colquitt and George, 2011) that have emerged alongside rapid social, economic and technological change include resource depletion, climate change, and biodiversity loss. Organizations lie at the heart of these issues: they are both part of the 'problem' and will be fundamental to any 'solution'. 
For-profit firms have ravaged both human and environmental resources in service of profits, while notfor-profit firms often drift from accomplishing their core mission for the lack of funding.

Organizations can reverse this damage by integrating growth, innovation, and efficiency associated with market pressures and shareholder demands along with the values, purpose, and impact associated with mission driven organizations and broader stakeholder interests. Yet effectively integrating these competing demands is challenging. Together, institutional theory and paradox theory can critically contribute to debates on these issues, particularly given the fundamental role of tensions and paradoxes in shaping their emergence and evolution (Jay, 2013; Smith et al., 2012; Gonin et al., 2013; Margolis and Walsh, 2003; Hahn et al., 2014). Taken together, these two theories can investigate both the exogenous and endogenous factors that surface competing demands, and explore organizational and individual approaches for accommodating competing demands simultaneously. For example, Ansari, Wijen and Grey (2013) use institutional theory to surface the tensions that emerged among divergent actors with varying societal level pressures trying to address climate change. They note an effective response highlighted in paradox theory, the critical role of both differentiating - recognizing the contributions of varying actors, while simultaneously integrating - developing an overarching, integrative frame that helps actors recognize their interconnections with one another. Building on existing research, future studies can explore the contradictory and interdependent nature associated with commercial, social and environmental expectations, and individual and organizational responses to engage these distinctions. Indeed, exploring how organizations can serve to exacerbate and/or solve the grand challenges of the world is surely necessary if management research is to engage the next generation of scholars, for whom such issues are powerfully resonant (cf., Lawrence et al.'s forthcoming discussion of the role of institutional work in addressing the complexity inherent in such challenges).

Conclusion

As our world continues to be more global, fast-paced, and integrated, long term success will increasingly depend on an organization's ability to address competing demands. Though institutional complexity and paradox theory offer divergent approaches to competing demands, together they can 
provide complementary insights. We hope these areas of complementarity can generate valuable future research. 


\section{Works Cited}

Andriopoulos C and Lewis MW. (2009) Exploitation-Exploration tensions and organizational ambidexterity: Managing paradoxes of innovation. Organization Science 20(4): 696-717.

Andriopoulos C and Lewis MW. (2010) Managing Innovation Paradoxes: Ambidexterity Lessons from Leading Product Design Companies. Long Range Planning 43(1): 104-122.

Ansari S, Wijen F and Gray B. (2013) Constructing a climate change logic: An institutional perspective on the "tragedy of the commons". Organization Science 24(4): 1014-1040.

Ashforth BE and Reingen PH. (2014) Functions of Dysfunction: Managing the Dynamics of an Organizational Duality in a Natural Food Cooperative. Administrative Science Quarterly.

Audia PG, Locke EA and Smith KG. (2000) The paradox of success: An archival and a laboratory study of strategic persistence following radical environmental change. Academy of Management Journal 43(5): 837-853.

Bartunek J. (1988) The dynamics of personal and organizational reframing. In: Quinn R and Cameron K (eds) Paradox and Transformation: Toward a Theory of Change in Organization and Management. Cambridge, MA: Ballinger, 137-162.

Battilana J. (2006) Agency and institutions: The enabling role of individuals' social position. Organization 13(5): 653-676.

Battilana J and Dorado S. (2010) Building sustainable hybrid organizations: The case of commercial microfinance organizations. Academy of Management Journal 53(6): 1419-1440.

Battilana J and Lee M. (2014) Advancing Research on Hybrid Organizing- Insights from the Study of Social Enterprises. The Academy of Management Annals 8(1): 397-441.

Battilana J, Sengul M, Pache A-C, et al. (2014) Harnessing Productive Tensions in Hybrid Organizations: The Case of Work Integration Social Enterprises. Academy of Management Journal.

Beech N, Burns H, de Caestecker L, et al. (2004) Paradox as invitation to act in problematic change situations. Human Relations 57(10): 1313-1332.

Besharov ML. (2014) The relational ecology of identification: How organizational identification emerges when individuals hold divergent values. Academy of Management Journal.

Besharov ML and Smith WK. (2014) Multiple Institutional Logics in Organizations: Explaining their Varied Nature and Implications. Academy of Management Review 39(364-381).

Cameron K. (1986) Effectiveness as paradox: Consensus and conflict in conceptions of organizational effectiveness. Management Science 32(5): 539-553.

Chen MJ. (2002) Transcending paradox: The Chinese "Middle Way" Perspective. Asia Pacific Journal of Management 19: 179-199.

Christensen C and Bower J. (1996) Customer Power, Strategic Investment and the Failure of Leading Firms. Strategic Management Journal 17(3): 197-218.

Colquitt JA and George G. (2011) Publishing in AMJ-part 1: topic choice. Academy of Management Journal 54(3): 432-435.

Creed WD, Hudson BA, Okhuysen GA, et al. (2014) Swimming in a sea of shame: incorporating emotion into explanations of institutional reproduction and change. Academy of Management Review 39(3): 275-301.

Drucker PF. (1984) A new look at corporate social responsibility. McKinsey Quarterly 4(Autumn): 17-28.

Farjoun M. (2010) Beyond Dualism: Stability and Change as Duality. Academy of Management Review 35(2): 202-225.

Ford J and Backoff R. (1988) Organizational Change In and Out of Dualities and Paradox. In: Quinn R and Cameron K (eds) Paradox and Transformation: Toward a Theory of Change in Organization and Management. Cambridge, MA: Ballinger, 81-121.

Ford JD and Ford LW. (1994) Logics of dualities, contradiction and attraction in change. Academy of Management Review 19(4): 756-795. 
Friedland R and Alford RR. (1991) Bringing Society Back in: Symbols, Practices, and Institutional Contradictions. In: Powell W and DiMaggio PJ (eds) The New Institutionalism in Organizational Analysis. Chicago: University of Chicago Press, 232-266.

Gilbert C. (2005) Unbundling the Structure of Inertia: Resource versus Routine Rigidity. Academy of Management Journal 48(5): 741-763.

Glynn MA. (2000) When cymbals become symbols: Conflict over organizational identity within a symphony orchestra. Organization Science 11(3): 285-298.

Gonin M, Besharov ML and Smith WK. (2013) Managing Social-Business Tensions: A Review and Research Agenda for Social Enterprise. Academy of Management Proceedings 2013: upcoming.

Goodrick E and Reay T. (2011) Constellations of institutional logics: Changes in the professional work of pharmacists. Work and Occupations 38(3): 372-416.

Greenwood R, Díaz AM, Li SX, et al. (2010) The Multiplicity of Institutional Logics and the Heterogeneity of Organizational Responses. Organization Science 21(2): 521-539.

Greenwood R, Raynard M, Kodeih F, et al. (2011) Institutional complexity and organizational responses. Academy of Management Annals 5(1): 317-371.

Hahn T, Preuss L, Pinkse J, et al. (2014) Cognitive Frames in Corporate Sustainability: Managerial Sensemaking with Paradoxical and Business Case Frames. Academy of Management Review.

Huy QN. (2002) The Emotional Balancing of Organizational Continuity and Radical Change: The Contribution of Middle Managers. Administrative Science Quarterly 47: 31-69.

Jarzabkowski P and Le J. (2016) We have to do this and that? You must be joking. Construcing and responding to paradox through humor. Organization Studies.

Jay J. (2013) Navigating Paradox as a Mechanism of Change and Innovation in Hybrid Organizations. Academy of Management Journal 56(1): 137-159.

Kets de Vries MFR. (1995) Organizational paradoxes: Clinical approaches to management., New York: Routledge.

Klein KJ, Ziegert JC, Knight A, et al. (2006) Dynamic Delegation: Shared, Hierarchical and Deindividualized Leadership in Extreme Action Teams. Administrative Science Quarterly 51: 590-621.

Kostova T and Roth K. (2002) Adoption of an organizational practice by subsidiaries of multinational corporations: Institutional and relational effects. Academy of Management Journal 45(1): 215233.

Kostova T, Roth K and Dacin MT. (2008) Institutional theory in the study of multinational corporations: A critique and new directions. Academy of Management Review 33(4): 994-1006.

Lawrence TB, Suddaby R and Leca B. (2009) Institutional work: Actors and agency in institutional studies of organizations: Cambridge university press.

Lewis MW. (2000) Exploring paradox: Toward a more comprehensive guide. Academy of Management Review 25(4): 760-776.

Luscher L and Lewis MW. (2008) Organizational change and managerial sensemaking: Working through paradox. Academy of Management Journal 51(2): 221-240.

Margolis JD and Walsh J. (2003) Misery loves company: Rethinking social initiatives by business. Administrative Science Quarterly 48(2): 268-305.

McPherson CM and Sauder M. (2013) Logics in action managing institutional complexity in a drug court. Administrative Science Quarterly: 0001839213486447.

Miron-Spektor E, Gino F and Argote L. (2011) Paradoxical frames and creative sparks: Enhancing individual creativity through conflict and integration. Organizational Behavior and Human Decision Processes 116(2): 229-240.

Murnighan JK and Conlon D. (1991) The Dynamics of Intense Work Groups: A Study of British String Quartets. Administrative Science Quarterly 36(2): 165-186.

Nigam A and Ocasio W. (2010) Event attention, environmental sensemaking, and change in institutional logics: An inductive analysis of the effects of public attention to Clinton's health care reform initiative. Organization Science 21(4): 823-841. 
Pache AC and Santos F. (2010) When worlds collide: The internal dynamics of organizational responses to conflicting institutional demands. Academy of Management Review 35(3): 455-476.

Poole MS and Van de Ven A. (1989) Using paradox to build management and organizational theory. Academy of Management Review 14(4): 562-578.

Putnam L, Fairhurst G and Banghart S. (Forthcoming) Contradictions, Paradoxes and Dialectics in Organizations: A Constituative Approach. Academy of Management Annals.

Quinn R and Cameron K. (1988) Paradox and Transformation: A Framework for Viewing Organization and Management. In: Quinn R and Cameron K (eds) Paradox and Transformation: Toward a Theory of Change in Organization and Management. Cambridge, MA: Ballinger, 289-308.

Quirke L. (2013) Rogue resistance: Sidestepping isomorphic pressures in a patchy institutional field. Organization Studies: 0170840613483815.

Raaijmakers AGM, Vermeulen PAM, Meeus MTH, et al. (2015) I need time!: Exploring pathways to compliance under institutional complexity. Academy of Management Journal 58(1): 85-110.

Raisch S and Birkinshaw J. (2008) Organizational Ambidexterity: Antecedents, Outcomes, and Moderators. Journal of Management 34: 375-409.

Reay T and Hinings CR. (2009) Managing the rivalry of competing institutional logics. Organization Studies 30(6): 629-652.

Reinecke J and Ansari S. (2015) When Times Collide: Temporal Brokerage at the Intersection of Markets and Developments. Academy of Management Journal 58(2): 618-648.

Rothenberg A. (1979) The Emerging Goddess, Chicago: University of Chicago Press.

Schad J, Lewis M, Raisch S, et al. (2016) Paradox Research in Management Science: Looking Back to Move Forward. Academy of Management Annals.

Slawinski N and Bansal P. (2015) Short on Time: Intertemporal Tensions in Business Sustainability. Organization Science Articles in Advance.

Smets M, Jarzabkowski P, Burke GT, et al. (2015) Reinsurance Trading in Lloyd's of London: Balancing Conflicting-yet-Complementary Logics in Practice. Academy of Management Journal 58(3): 932970.

Smets M, Morris T and Greenwood R. (2012) From practice to field: A multilevel model of practicedriven institutional change. Academy of Management Journal 55(4): 877-904.

Smith K and Berg D. (1987) Paradoxes of group life, San Francisco: Josey-Bass.

Smith W. (2014) Dynamic Decision Making: A Model of Senior Leaders Managing Strategic Paradoxes. Academy of Management Journal 57(6): 1592-1623.

Smith WK, Besharov ML, Wessels A, et al. (2012) A Paradoxical Leadership Model for Social Entrepreneurs: Challenges, Leadership Skills, and Pedagogical Tools for Managing Social and Commercial Demands Academy of Management Learning \& Education 11(3): 463-478.

Smith WK and Lewis MW. (2011) Toward a theory of paradox: A dynamic equilibrium model of organizing. Academy of Management Review 36(2): 381-403.

Smith WK, Lewis MW and Tushman ML. (2011) Organizational sustainability: Organization design and senior leadership to enable strategic paradox. In: Cameron K and Spreitzer G (eds) The Oxford Handbook of Positive Organizational Scholarship. New York, NY: Oxford University Press, 798-810.

Smith WK and Tushman ML. (2005) Managing strategic contradictions: A top management model for managing innovation streams. Organization Science 16(5): 522-536.

Sundaramurthy C and Lewis MW. (2003) Control and Collaboration: Paradoxes of Governance. Academy of Management Review 28(3): 397-415.

Thornton PH, Ocasio W and Lounsbury M. (2012) The Institutional Logics Perspective: A New Approach to Culture, Structure and Process, Cambridge: Oxford University Press.

Tracey P. (forthcoming) Spreading the Word: The Microfoundations of Institutional Persuasion and Conversion. Organization Science.

Tracey P, Phillips N and Jarvis O. (2011) Bridging institutional entrepreneurship and the creation of new organizational forms: A multilevel model. Organization Science 22(1): 60-80. 
Tripsas M and Gavetti G. (2000) Capabilities, Cognition and Inertia: Evidence from Digital Imaging. Strategic Management Journal 18(Summer Special Issue): 119-142.

Vince R and Broussine M. (1996) Paradox, defense and attachment: Accessing and working with emotions and relations underlying organizational change. Organization Studies 17(1): 1-21.

Voronov M and Vince R. (2012) Integrating emotions into the analysis of institutional work. Academy of Management Review 37(1): 58-81.

Weick K, Sutcliffe KM and Obstfeld D. (1999) Organizing for high reliability: Processes of collective mindfulness. In: Sutton RI and Staw BM (eds) Research In Organizational Behavior. Stamford: JAI Press, 81-123.

Wright A, Zammuto R and Liesch P. (forthcoming) Maintaining the values of a profession: Institutional work and moral emotions in the emergency department. Academy of Management Journal.

Wright AL and Zammuto RF. (2013) Wielding the willow: Processes of institutional change in English county cricket. Academy of Management Journal 56(1): 308-330.

Zahra SA, Gedajlovic E, Neubaum D, et al. (2009) A typology of social entrepreneurs: Motives, search processes and ethical challenges. Journal of Business Venturing 24(5).

Zilber TB. (2013) Institutional logics and institutional work: Should they be agreed. Research in the Sociology of Organizations 39: 77-96. 
TABLE: Underlying Assumptions - Institutional Complexity and Paradox Theory

\begin{tabular}{|c|c|c|}
\hline & Institutional Complexity & Paradox Theory \\
\hline Source of competing demands & $\begin{array}{l}\text { Competing demands emerge } \\
\text { from plurality of logics at the } \\
\text { field/societal level. } \\
\text { Increased environmental } \\
\text { plurality fosters growing } \\
\text { experiences of competing } \\
\text { demands in organizations. }\end{array}$ & $\begin{array}{l}\text { Competing demands are } \\
\text { inherent in organizations, } \\
\text { emerging through the act of } \\
\text { organization; or emerge through } \\
\text { relational dynamics or } \\
\text { individual sense making. } \\
\text { Increased environmental } \\
\text { plurality, scarcity and change, as } \\
\text { well as individual sense making } \\
\text { fosters growing experiences of } \\
\text { competing demands in } \\
\text { organizations. }\end{array}$ \\
\hline Nature of competing demands & $\begin{array}{l}\text { Multiple logics can co-exist } \\
\text { within on organization, though } \\
\text { studies often simplify dynamics } \\
\text { to focus on two logics. } \\
\text { Multiple logics are often } \\
\text { contradictory, but can also be } \\
\text { complementary. }\end{array}$ & $\begin{array}{l}\text { Two elements existing in } \\
\text { relation to one another. High } \\
\text { number elements may involve } \\
\text { different dynamics. } \\
\text { Tensions are both contradictory } \\
\text { (oppositional, inconsistent, } \\
\text { conflictual) and interdependent } \\
\text { (interrelated, synergistic, } \\
\text { mutually constituted). }\end{array}$ \\
\hline $\begin{array}{l}\text { Challenges and responses to } \\
\text { competing demands }\end{array}$ & $\begin{array}{l}\text { Competing logics foster } \\
\text { challenges of external } \\
\text { legitimacy and internal conflict } \\
\text { that need to be resolved. } \\
\text { Competing logics can be } \\
\text { managed by implementing } \\
\text { effective structures at the } \\
\text { organizational and field level. }\end{array}$ & $\begin{array}{l}\text { Competing demands persist over } \\
\text { time, and cannot be resolved, } \\
\text { but if effectively engaged can } \\
\text { foster creativity and } \\
\text { sustainability. } \\
\text { Paradoxes provoke dynamic } \\
\text { interactions, and require } \\
\text { ongoing, processual responses. }\end{array}$ \\
\hline
\end{tabular}


Wendy K. Smith (smithw@udel.edu) is Associate Professor of Management in the Lerner College of Business and Economics, University of Delaware and Research Fellow with the Centre for Social Innovation at the Judge School of Business, Cambridge University. Her research explores how leaders and their organizations manage strategic paradoxes, including tensions between exploration and exploitation, social mission and financial performance, and global integration and local demands. She has published her research in journals such as the Academy of Management Review, Academy of Management Journal, Academy of Management Annals, Organization Science and Harvard Business Review. She received her Ph.D. from Harvard Business School.

Paul Tracey (p.tracey@jbs.cam.ac.uk) is Professor of Innovation and Organization and Academic Director of the Centre for Social Innovation at the University of Cambridge Judge Business School. Between 2011 and 2013 he was an Economic and Social Research Council Mid-career Fellow. His research interests include social innovation, regional innovation, and institutional change. He has published his research in journals such as the Academy of Management Review, Academy of Management Journal, Organization Science and Journal of Marketing. He received his Ph.D. from the University of Stirling. 